\title{
HÁBITOS POSTURAIS: DIAGNÓSTICO A PARTIR DE FOTOGRAFIAS
}

Ivete de Aquino Freire

Tatiane Gomes Teixeira

Célio Reis Sales

\section{Resumo}

O presente ensaio tem como proposta central apontar a possibilidade do uso da imagem fotográfica para análise dos hábitos posturais em escolares. Nesta ótica propomos a utilização deste instrumento tanto para o diagnóstico como acompanhamento da efetividade de programas de educação postural. A fotografia pode ser um forte aliado no programa de educação postural na medida em que requer um equipamento de baixo custo, é altamente motivadora e contribui para sistematização de ações direcionadas as peculiaridades posturais de cada indivíduo e do coletivo. Pela simplicidade do instrumento, pode ser utilizado por qualquer indivíduo, requerendo sim alguns conhecimentos específicos para sua análise no âmbito dos hábitos posturais.

\section{Palavras-Chave:}

Educação postural; Hábitos posturais; Fotografias

\section{POSTURAL HABITS: DIAGNOSIS FROM PHOTOS}

Ivete de Aquino Freire

Tatiane Gomes Teixeira

Célio Reis Sales

\begin{abstract}
The present essay has as central proposal to point the possibility of using the photographic image for the analysis on posture habits on schoolchildren. In this view we propose the utilization of this instrument as the diagnostic as the to accompaniment of efficiency on programs of posture education. The photographic can be an important allied in the program on posture education, because it requires an equipment of low cost, it is a great motivator and it contributes to the systematization of directive actions to the particulars posture of each individual and collective. For the simplicity of the instrument, it can be used as far any individual, askings a some specifics knowledge for the analysis in the scope of posture habits.
\end{abstract}

Key-Words:

Posture education; Posture habits; Photographics 


\section{Introdução}

Crianças em idade escolar passam entre 4 e 5 horas na escola. Nesta ocasião, estas permanecem sentadas a maior parte do tempo, aspecto que demanda uma atenção especial por parte dos pais, educadores e demais estudiosos da postura corporal. $\mathrm{O}$ ambiente escolar tem se tornado aquele que mais favorece a postura de sustentação na posição sentada durante várias horas. Por diversos fatores, inclusive pela elevada quantidade de alunos em sala e a necessidade de manutenção da disciplina, os professores são rígidos quanto ao controle dos movimentos das crianças dentro da sala de aula. Somado a esta problemática, normalmente as cadeiras e mesas escolares não são ajustáveis à estatura das crianças, além de serem desconfortáveis. Estas circunstâncias são altamente favoráveis à adoção de uma postura mais cômoda, que na maioria das vezes é inadequada para a saúde postural. Quase sempre os móveis não favorecem o apoio adequado e simultâneo à coluna vertebral e aos membros inferiores. As crianças pequenas são as mais prejudicadas, devido a padronização de carteiras escolares maiores, para prolongar ao máximo seu uso e estendê-lo a todas as faixas etárias. Tendo em vista que as crianças e adolescentes passam diversas horas neste ambiente, sem as informações voltadas a educação postural, estas acabam por acostumar-se com posturas incorretas. Estas formas de posicionar o corpo, aos poucos vão se consolidando em hábitos posturais, que são considerados inadequados e prejudiciais a saúde postural. Desse modo as crianças e adolescentes são considerados os grupos mais vulneráveis a desvios da coluna vertebral.

Segundo um estudo de Freire e Mendonça (2003) os problemas posturais são mais comuns em escolares do que se imagina. Estes autores encontraram percentuais elevados de alterações posturais (escoliose, hipercifose torácica e hiperlordose lombar) junto a esta população. A partir de outro estudo, Costa e Freire (2004) discutem o estilo de vida sedentária na infância como fator determinante dos problemas posturais. Os autores ao observarem sessões de Educação Física na escola, verificaram que as aulas não estão contemplando a manutenção e desenvolvimento de uma boa postura. Esta conclusão se justifica pela falta de exercícios direcionados ao fortalecimento da musculatura responsável pela postura e movimentos que proporcionam aquisição de consciência corporal, indispensáveis no processo de educação postural. Verificou-se nas aulas forte tendência à mera repetição do movimento, destacando-se atividades pouco dinâmicas e criativas, privilegiando o condicionamento físico e o fortalecimento dos grandes grupos musculares. Estes e outros estudos têm demonstrado a necessidade de se trabalhar na escola tendo como ponto de partida o diagnóstico dos problemas posturais com vistas a investir na prevenção de futuras patologias. 
Neste ensaio discutimos a questão postural: os hábitos, estratégias para diagnóstico e mecanismos para elaboração de uma proposta de educação postural no ambiente escolar. A partir de fundamentação teórica e experiência, apontam-se alguns caminhos para a implementação do uso da imagem fotográfica como um instrumento de diagnóstico de hábitos posturais. Tem-se como ponto de partida uma reflexão teórica sobre os problemas de saúde que podem ter origem no cotidiano escolar a partir da adoção de posturas inadequadas. Aborda-se também a importância da educação postural no contexto da saúde, sobretudo no seu aspecto preventivo.

\section{A Postura Corporal e o Contexto Escolar}

Postura corporal é um conceito bastante complexo. Depende de inúmeras variáveis tais como determinantes genéticos; fatores neuromusculares, como equilíbrio e flexibilidade; consciência corporal; aspectos relativos a limitações físicas, como existência de lesões articulares e musculares, dentre outras. Considerando esta diversidade de determinantes, não há consenso na literatura sobre o que se considera uma postura correta. Para Kendall e Coll apud Knoplick, (1986), por exemplo, a "postura ideal” refere-se àquela posição que envolve o mínimo de estiramento e de stress das estruturas corporais, com menos gasto de energia para obter o máximo de eficiência no uso do corpo. Na tentativa de apontar mais um caminho sobre esta questão, pode-se dizer que uma postura satisfatória para a saúde e bem-estar implica necessariamente no respeito à postura biomecanicamente correta considerando-se a harmonia e equilíbrio do sistema neuromúsculo-esquelético individual. Por outro lado, uma das características do que se considera má postura é o posicionamento do indivíduo fora dos padrões da linha de gravidade conduzindo a musculatura uma sobrecarga mecânica e alterações dos padrões músculo-esqueléticos.

Apesar de sua relevância, o tema postura corporal é assunto pouco discutido na sociedade, especialmente nas escolas. É sabido que nas fases iniciais da vida a coluna vertebral facilmente se ajusta às necessidades individuais e ambientais. Os longos períodos que os indivíduos normalmente passam sentados ou assumindo posturas inativas, aliados ao sedentarismo, influenciam negativamente não apenas a musculatura da coluna vertebral, mas também nas estruturas passivas desta. Estudos de Zapater et al (2004) indicam que permanecer sentado por mais de 45 a 50 minutos sem interrupção é um fator de risco para a saúde. Num estudo anterior, Coury (1994) já afirmava que nestes casos, a pressão intra-discal aumenta para mais de $70 \%$. Tal influência se dá principalmente nas crianças e adolescentes. Neste aspecto, são determinantes para a saúde postural, os hábitos adotados pelos indivíduos neste momento da 
vida. Compreendem-se os hábitos posturais como um conjunto de posturas utilizadas mais comumente por um indivíduo em seu cotidiano.

Apesar das escassas publicações no Brasil, o estudo dos hábitos posturais tem se tornado uma importante alternativa no processo preventivo de problemas na coluna vertebral. Tribastone (2001) ao referir-se a questão preventiva, cita que os hábitos incorretos são fatores influenciadores para as alterações dinâmicas do corpo. Ainda neste sentido, Rasch e Burke (1997) citam que as posturas utilizadas mais comumente por um indivíduo em seu cotidiano são os principais determinantes da postura corporal. O estudo dos hábitos posturais se torna relevante na medida em que estes são considerados ações modificáveis. Daí, se compreende que quando mais precoce forem obtidas informações sobre as posturas corporais assumidas, mais fácil se torna a prevenção de doenças e síndromes dolorosas da coluna.

Estas síndromes ocupam a primeira posição no Brasil entre pagamento de auxílio-doença e são a terceira causa dos pedidos de aposentadoria por invalidez no país (FERNANDES, 2000). Portanto verifica-se que, embora aparentemente sem importância, trata-se de uma questão que acomete grande parte dos brasileiros. Neste sentido a melhor forma de evitar ou minimizar as patologias da coluna é a prevenção. Para a realidade brasileira, sobretudo quando nos referimos à escola pública, parecer ser o profissional de Educação Física o elemento mais acessível para iniciar uma proposta de educação postural. Neste contexto, o diagnóstico da realidade é um fator determinante, seja com fim exclusivo de subsidiar a prática da Educação física Escolar, seja na perspectiva de elaboração de projetos educativos mais amplos voltados aos cuidados com a saúde postural. Um programa desta natureza tem como importante aliado a informação, que passa necessariamente por uma reflexão dos conceitos e atitudes adotadas no cotidiano. De igual importância, situamos uma adequada rotina de exercícios; que abranjam todas as cadeias musculares responsáveis pela sustentação da coluna, considerando as valências físicas que atuam mais diretamente na manutenção saudável destas estruturas, aliado à consciência corporal. Complementando esta idéia, Braciali (2000) cita que as orientações fornecidas pelos educadores às crianças podem prevenir os desvios posturais e direcioná-los a melhores atitudes posturais. Para isso, faz-se necessário a observação do ambiente escolar bem como as posturas adotadas pelos alunos neste ambiente. Desta observação, que resultará em diagnóstico, será possível fomentar junto à comunidade escolar discussões sobre a importância da postura para a saúde e rendimento escolar das crianças. 


\section{Educação Postural e Possibilidade de Mudança de Hábitos}

O trabalho de educação postural é um processo educacional, que se pauta no fornecimento de informações para um grupo de indivíduos sobre a questão postural. A expectativa e perspectiva é que os hábitos inadequados sejam modificados e medidas preventivas para o impedimento de doenças da coluna se estabeleçam.

A partir de experiência realizada com crianças de comunidade ribeirinha (FREIRE; TEIXEIRA; SALES, 2007) verificaram que este tipo de trabalho precisa ser realizado diariamente, especialmente com crianças. Trata-se de um assunto que gera pouco interesse ao universo infantil. Por esse motivo é essencial estimular a criança através de atrativos que a façam perceber a importância da postura na vida cotidiana, conscientizando-a sobre as possíveis conseqüências de hábitos inadequados. Por estas características, um projeto de educação postural deve caminhar no sentido de ser uma proposta da comunidade escolar, que envolva principalmente pais e professores de diversas disciplinas. Neste prisma, Oliveira (1996) relata que ao trabalhar com os professores lança-se mão de uma importante ferramenta, a qual tende a facilitar assimilação por parte das crianças sobre os conteúdos trabalhados. Isso acontece pelo contato cotidiano destes com as crianças. Além deste aspecto, a possibilidade de serem controlados os aspectos físicos do ambiente escolar é aumentada.

É importante destacar que os resultados de qualquer trabalho educacional só podem ser observados a médio e longo prazo. Entretanto, no âmbito da educação postural, com enfoque nos hábitos, pequenas mudanças de atitudes e forma de pensar podem ser observadas em curto prazo.

Quando adequadamente trabalhada a educação postural pode ser bastante efetiva. Um estudo de Fernandes (2007) utilizando a educação postural apontou que as crianças realmente aprendem com este trabalho. No referido estudo foi observada melhoria nos hábitos posturais relacionadas ao carregamento de mochilas. Para que estes resultados sejam obtidos é necessário atuar no fornecimento de informações sobre a questão postural.

No que diz respeito às estratégias de ensino, Zapater (2004) relata que as técnicas de feedback são importantes e geralmente efetivas nas práticas educacionais. Esta técnica compreende uma revisão constante dos conteúdos apresentados e a evolução dos mesmos de acordo com a fixação apresentada 
pelos indivíduos. Neste contexto é interessante a utilização desta técnica com crianças, especialmente para promover a conscientização para a importância da questão postural.

Um aspecto importante no trabalho de educação postural é a verificação dos desvios posturais potenciais e dos hábitos já instalados nas crianças. Para detectar os desvios deve ser realizada uma avaliação postural, através de um dos vários instrumentos de diagnose relatados na literatura. Para identificação dos hábitos posturais. Após a análise dos resultados sugere-se que as crianças sejam atendidas de acordo com as suas necessidades, podendo ser encaminhadas a outros profissionais, como fisioterapeutas e ou ortopedistas. Na escola através das aulas de Educação Física podem ser potencializados o fortalecimento das musculaturas fragilizadas, o alongamento daquelas encurtadas, além da consciência corporal.

Outra análise importante no contexto da educação postural é a averiguação dos hábitos posturais adotados. Esta análise se faz importante pela possibilidade de direcionar o trabalho educacional sobre as atitudes posturais encontradas com maior freqüência. Neste prisma, conhecer os hábitos mais prejudiciais e atuar sobre a correção dos mesmos é uma ótima alternativa para minimizar ou prevenir posturas inadequadas em ambiente escolar.

\section{O Uso da Imagem Fotográfica para Análise de Hábitos Posturais}

Quando foram inventadas, as imagens fotográficas se refletiam num importante facilitador do trabalho de pintores, devido as suas características, citadas por Sene (2005), de fornecer às cenas notável semelhança com a realidade. Mais adiante, as fotografias começaram a ser utilizadas em ambiente científico na medicina, para realização de estudos de doenças mentais. Isto aconteceu no século XIX, quando se acreditava que a imagem produzida poderia facilitar detalhes sobre sintomas que não poderiam ser perceptíveis a olho nu (FRIZOT apud HOCHMAN et al. 2002). Já no mundo moderno e contemporâneo as fotografias ganharam espaço e suas vantagens começaram a ser utilizadas para comprovação de fatos em diversas áreas do conhecimento.

No âmbito da postura corporal verifica-se um grande número publicações que indicam protocolos de avaliação de fotografias ou outras formas de imagens (RENNÓ, 2004; DENYS-STRUF, 1995; VIEIRA, 2001; BARAÚNA, 2006, TAKAHASHI, 1992). O reconhecimento do uso deste instrumento acontece pelo fato deste recurso imagético favorecer a análise das estruturas corporais, e em alguns casos, do equilíbrio, valência física importante na postura corporal. Os protocolos de análise da postura, constantes 
na literatura, resultam em dados mais cautelosos e certificados do que outras que fazem uso de técnicas subjetivas, como à observação e a palpação, por exemplo. Este recurso imagético tem sido prioritariamente utilizado pela área médica ou fisioterapêutica. No contexto educacional, especialmente no âmbito da Educação Física com enfoque na educação postural, o uso desta tecnologia parece ser pouco explorada. Os protocolos constantes nos referenciais teóricos, orientados por experimentos, apontam para a necessidade do uso de equipamentos de alta tecnologia, disponíveis apenas nos laboratórios, portanto, inviáveis para a realidade escolar.

No que diz respeito a identificação dos hábitos posturais, alguns trabalhos foram publicados. Dentre estes, destaca-se o de Rebolho (2005). O estudo em questão sugere o uso de um questionário para avaliar a postura das crianças em situações cotidianas. Através do referido instrumento podem ser obtidas importantes informações sobre os hábitos instalados. Nesta mesma perspectiva pode ser citado o trabalho de Fernandes (2007), que a partir de técnicas de observação dos indivíduos in loco, verificou os hábitos posturais de alunos referente ao transporte de mochilas escolares. Os instrumentos de avaliação e/ou diagnóstico de hábitos posturais localizados na literatura são do tipo questionários, formulários ou roteiros para seqüência de observação da postura dos indivíduos.

O que se propõe neste ensaio é o uso das imagens fotográficas como recurso para estudo dos hábitos posturais. Esta proposição se dá por diversos aspectos. Pelas suas características imagéticas, as fotografias podem ser utilizadas como recurso de identificação e acompanhamento de mudanças na postura. A técnica possibilita averiguar reais mudanças e promover adaptações efetivas no aspecto postural. Isto é possível porque este tipo de figura permite uma abordagem real em situações fidedignas. Usando as palavras de Sene (2005), podemos dizer que a imagem possibilita escrever as observações do todo ou parte do processo evolutivo de determinada atitude postural. A postura corporal, por ser algo que se exterioriza permite sua identificação através do recurso imagético simples como a fotografia comum.

O registro fotográfico alcançou na sociedade atual posição favorável no cotidiano das pessoas: independente da faixa etária. A acessibilidade econômica favorável a um equipamento fotográfico, atrelada à tecnologia que, por exemplo, reúne em um aparelho de celular funções de máquina fotográfica, entre outras, tem potencializado a prática do registro fotográfico em diversos ambientes e ocasiões. É comum observarmos, principalmente nas zonas urbanas, crianças e jovens adotarem como diversão ou passatempo "fazer fotos". 
Partindo destas características facilitadoras, propõe-se a utilização do registro fotográfico como recurso de observação das posturas assumidas pelos indivíduos no cotidiano escolar. Na rotina da escola, os indivíduos assumem posturas variadas apesar de como já foi dito, na maior parte do tempo permanecerem sentados. O registro imagético permite a demonstração de forma acessível das diversas posturas assumidas no cotidiano como sentar-se, posicionar-se de pé sem deslocamento, levantar-se, caminhar, levantar objetos do chão entre outras situações.

O uso deste instrumento torna possível a realização de uma análise diferenciada daquelas atualmente relatadas na literatura, já que pode proporcionar a visualização imediata da atitude postural. A partir destes dados diversas ações podem ser sistematizadas como, por exemplo: estudo das atitudes posturais no cotidiano, auto-leitura da atitude postural assumida pelos indivíduos a partir de uma base teórica, estudo do mobiliário escolar, do contexto como um todo e da indumentária no âmbito da postura corporal. Em termos descritivos, a postura corporal depende de uma série de fatores, especialmente físicos. Como citam Kock e Ries (2004) são de grande influência as dimensões situacional e física do indivíduo.

O uso da fotografia no contexto da educação postural se dá na medida em que este último conceito envolve duas variáveis importantes: percepção e conscientização corporal. A fotografia favorece a autovisualização da postura assumida, o que pode ser um fator importante para a percepção e posterior modificação de algum hábito inadequado; ou reforço das atitudes consideradas satisfatórias para a saúde postural. Desse modo, a fotografia representa uma ferramenta adicional para um trabalho voltado a educação postural.

Portanto a educação postural envolve mudança de hábitos. Neste sentido para a modificação de algum hábito inadequado é necessário que as pessoas integradas neste processo educativo tenham consciência de sua situação postural. Esta conscientização pode se dar através da percepção e visualização de sua imagem. Tal delimitação representa uma ferramenta adicional para a atuação direcionada do profissional.

Embora aqui se esteja sugerindo o uso da fotografia como recurso para diagnose de hábitos posturais, defende-se que esta avaliação não pode se dar de forma solta e desconectada de um projeto, sob pena de perder sua finalidade na perspectiva aqui proposta. Sugere-se que a avaliação neste caso, faça parte de um 
ARTIGO

programa de educação postural mais amplo no qual o levantamento de hábitos posturais a partir de fotografias, seja uma das estratégias presentes.

Inspirados pelo questionário de Rebolho (2005) para estudo de hábitos posturais em crianças, propomos a utilização de alguns parâmetros a verificação dos hábitos posturais a partir de fotografias. Estes parâmetros, expressos na Quadro 1, orientam tanto para o registro da imagem quanto para sua análise. Indicam a posição do corpo a ser observada, os aspectos gerais, o segmento corporal e a classificação do hábito. Esta última categoria tem a função de qualificar o hábito a fim de torná-lo produtivo no âmbito de um projeto voltado a educação postural. Estes parâmetros podem ser ampliados, sintetizados ou adaptados, de acordo com a intenção da proposta. Dependendo da turma e da metodologia adotada pelo projeto estes parâmetros podem ser analisados tanto de forma individual como coletivamente. Afim de que as imagens sejam utilizadas no âmbito dos hábitos posturais, o registro fotográfico precisa ser feito em vários dias e em distintos momentos do cotidiano escolar, consideradas principalmente situações reais da rotina dos alunos.

Sugere-se que os registros fotográficos sejam realizados pelos próprios alunos, partindo de um trabalho de sensibilização e conscientização do projeto a ser desenvolvido. Uma das etapas da proposta pode ser a oferta de um mini-curso de fotografia, a ser ministrado por algum membro da comunidade escolar. 
Figura 1- Parâmetros para registro e análise de hábitos posturais através de fotografias

\begin{tabular}{|c|c|c|c|c|}
\hline Posição & $\begin{array}{l}\text { Aspectos a serem } \\
\text { observados }\end{array}$ & $\begin{array}{l}\text { Segmento } \\
\text { corporal }\end{array}$ & Hábito positivo & Hábito Negativo \\
\hline \multirow[t]{2}{*}{ Sentado } & \multirow[t]{2}{*}{$\begin{array}{l}\text { Utilização do } \\
\text { móvel }\end{array}$} & Posição dos pés & $\begin{array}{l}\text { Totalmente apoiados no solo. } \\
\text { Se o móvel for inadequado } \\
\text { para o tamanho da criança, os } \\
\text { pés normalmente não tocam o } \\
\text { solo para que adote a postura } \\
\text { adequada da coluna. }\end{array}$ & $\begin{array}{l}\text { Parcialmente apoiados no } \\
\text { solo ou não apoiados }\end{array}$ \\
\hline & & Posição da coluna & $\begin{array}{l}\text { Ereta e adequadamente } \\
\text { apoiada na cadeira. No caso } \\
\text { de móvel inadequado por } \\
\text { tamanho grande, pode apoiar } \\
\text { os pés abaixo da cadeira e } \\
\text { manter a coluna bem } \\
\text { amparada no encosto. Mesmo } \\
\text { que as costas não alcancem o } \\
\text { encosto da cadeira, manter } \\
\text { uma postura ereta. }\end{array}$ & $\begin{array}{l}\text { Projeção da cabeça á frente e } \\
\text { acentuação da cifose } \\
\text { torácica. Se o móvel é } \\
\text { inadequado, ajusta-se à } \\
\text { postura mais confortável: } \\
\text { fica com as costas apoiadas e } \\
\text { pés soltos; ou costas } \\
\text { curvadas; pés soltos e coluna } \\
\text { curvada; ou todos estes } \\
\text { alternadamente a maior parte } \\
\text { do tempo. }\end{array}$ \\
\hline \multirow[t]{2}{*}{ De pé } & \multirow[t]{2}{*}{$\begin{array}{l}\text { Distribuição do } \\
\text { equilíbrio do peso }\end{array}$} & Quadril e coxas & $\begin{array}{l}\text { Totalmente apoiados no } \\
\text { assento }\end{array}$ & $\begin{array}{l}\text { Parcialmente apoiados no } \\
\text { assento ou não apoiadas }\end{array}$ \\
\hline & & Pernas & $\begin{array}{l}\text { Manter apoiado a maior parte } \\
\text { do tempo o peso do corpo } \\
\text { sobre ambas as pernas, com o } \\
\text { peso do corpo adequadamente } \\
\text { distribuído, e as pernas } \\
\text { levemente afastadas; }\end{array}$ & $\begin{array}{l}\text { Apoiar sempre em apenas } \\
\text { um dos membros inferiores, } \\
\text { porém alternar o tempo de } \\
\text { apoio entre as duas pernas; } \\
\text { Apoiar o peso do corpo } \\
\text { sempre em apenas uma das } \\
\text { pernas }\end{array}$ \\
\hline \multirow[t]{3}{*}{$\begin{array}{l}\text { Abaixar-se } \\
\text { para pegar } \\
\text { algum objeto } \\
\text { do solo }\end{array}$} & $\begin{array}{l}\text { Postura } \\
\text { hipercifótica e/ou } \\
\text { hiperlordótica. }\end{array}$ & Coluna e braços & $\begin{array}{l}\text { Coluna ereta e braços } \\
\text { relaxados ao longo do corpo. }\end{array}$ & $\begin{array}{l}\text { Manter a maior parte do } \\
\text { tempo postura de } \\
\text { recolhimento com as costas } \\
\text { curvadas apresentando } \\
\text { atitude hipercifótica } \\
\text { Manter a maior parte do } \\
\text { tempo os braços cruzados ou } \\
\text { relaxados ao longo do corpo, } \\
\text { adotando uma postura } \\
\text { hiperlordódica, ao projetar os } \\
\text { glúteos para trás e a região } \\
\text { peitoral para frente. }\end{array}$ \\
\hline & \multirow[t]{2}{*}{$\begin{array}{l}\text { Apoio excessivo } \\
\text { na coluna }\end{array}$} & \multirow[t]{2}{*}{ Joelho e tronco } & $\begin{array}{l}\text { Flexionar completamente os } \\
\text { joelhos, fazendo a flexão de } \\
\text { tronco apenas o suficiente para } \\
\text { alcançar o objeto; }\end{array}$ & $\begin{array}{l}\text { Flexiona parcialmente os } \\
\text { joelhos e pega o objeto sem } \\
\text { fazer flexão de tronco; }\end{array}$ \\
\hline & & & & $\begin{array}{l}\text { Manter os joelhos em } \\
\text { extensão, e fazer flexão de } \\
\text { tronco para alcançar o objeto }\end{array}$ \\
\hline
\end{tabular}




\section{Considerações Finais}

Consideramos que além de fornecer informações às crianças e pais sobre a questão postural, o programa de educação postural pode tornar-se mais produtivo e efetivo quando envolve a clientela através de atividades e estratégias motivadoras. A fotografia atende a esta expectativa. Além de ser um equipamento de baixo custo, portanto acessível a realidade brasileira, ao mesmo tempo é uma medida que contribui para ações direcionadas as peculiaridades de cada indivíduo e do coletivo. Sobre este aspecto acreditamos que a imagem fotográfica é uma ferramenta potencial para possibilitar uma relação de causa e conseqüência sobre os desvios posturais. Considerando estes aspectos, um trabalho preventivo e corretivo sobre os hábitos posturais pode tornar-se mais efetivo já que envolve de forma diferenciada e motivadora a clientela, favorecendo assim o alcance dos objetivos vinculados á saúde postural.

O registro fotográfico para estudo dos hábitos posturais não requer conhecimentos técnicos especializados. Pela relativa simplicidade do instrumento, pode ser utilizado por qualquer indivíduo, requerendo sim alguns conhecimentos específicos para sua análise no âmbito dos hábitos posturais.

A partir deste ensaio, sugerimos a colocação prática do uso da fotografia como instrumento de diagnóstico de hábitos posturais. Estudos desenvolvidos sobre os resultados desta aplicação poderão indicar a viabilidade do uso deste instrumento no processo de educação postural.

\section{Referências}

BARAUNA, M. A. et al. Avaliação do equilíbrio estático em indivíduos amputados de membros inferiores através da biofotogrametria computadorizada. Revista Brasileira de Fisioterapia, v. 10, n.1, p. 83-90, 2006

BRACIALI, L. M. P.; VILARTA, R. Aspectos a serem considerados na elaboração de programas de prevenção e orientação de problemas posturais. Revista Paulista de Educação Física, São Paulo, v. 2 n. 14, p. $159-171,2000$

COSTA, R. R. da; FREIRE, I. A. Análise da prática da Educação Física Escolar. Estudo dos exercícios físicos voltados para correção das alterações posturais. Relatório de Pesquisa apresentado a Universidade Federal de Rondônia/UNIR, Programa PIBIC. Porto Velho, 2004. 
COURY, H. J. C. Programa auto-instrucional para o controle de desconfortos posturais em indivíduos que trabalham sentados. 1994. Dissertação (Doutorado) - Faculdade de Educação, Universidade Estadual de Campinas, Campinas, 1994.

DENYS-STRUF, G. Cadeias musculares e articulares: o método GDS. São Paulo: Summus; 1995.

FERNANDES, S. M. S. Efeitos da orientação postural na utilização de mochilas escolares em estudantes de ensino fundamental. Dissertação (Mestrado). São Paulo. 2007.

FERNANDES, R. de C. P.; CARVALHO, F. M. Doença do disco intervertebral em trabalhadores da perfuração de petróleo. Caderno de Saúde Publica. Rio de Janeiro, v. 16, n. 3, p. 661-669. 2000.

FREIRE, I. A; MENDONÇA, F. S. Relatório final. Estudo dos níveis de saúde dos escolares do município de Porto Velho (Projeto). Avaliação Postural dos escolares da rede estadual e municipal de ensino da cidade de Porto Velho (Sub-projeto). Universidade Federal de Rondônia. Celafiu. Porto Velho. 2003.

FREIRE, A. F., TEIXEIRA, T.; SALES, C. R. Relatório Final. Projeto Calama: Ribeirinho do Madeira. Sub-projeto educação postural. Fundação Universidade Federal de Rondônia. Porto Velho, 2007.

HOCHMAN, G.; MELlO, M. T. B.; SANTOS, P. R. E. A malária em fato: imagens de campanhas e ações do Brasil da primeira metade do século XX. Revista História, Ciências, Saúde, Rio de Janeiro. v. 9, supl, p. 233-272. 2002

KOCK, K. de S.; RIES, L. G. K. A influência da personalidade na postura. Revista Fisioterapia Brasil. v. 5. n. 2.2004

KNOPLICK, J. Enfermidades da coluna vertebral.São Paulo: Panamed, 1986.

OLIVEIRA, R. J. P. Postura de crianças em sala de aula: um estudo diagnóstico. Dissertação (Mestrado em Educação) - Universidade Federal de São Carlos, São Carlos. 1996

RASCH, P. J.; BURKE, R. K. Cinesiologia e anatomia aplicada: a ciência do movimento humano. 5. ed., Rio de Janeiro: Guanabara Koogan, 1997.

REBOLHO, M. C. T. Efeitos da educação potural nas mudanças de hábitos em escolares de $1^{\mathrm{a}}$ a $4^{\mathrm{a}}$ série do ensino fundamental. Dissertação (Mestrado). São Paulo. 2005

RENNÒ, A. C. M.; et al. Correlações entre grau de cifose torácica, função pulmonar e qualidade de vida em mulheres com osteoporose. Revista Fisioterapia da Universidade São Paulo, São Paulo, p. 24- 31, São Paulo. 2004.

SENE, J. L. L. Fotografia:ensino é pesquisa. XXVIII Congresso Brasileiro de Ciência da Comunicação. Rio de Janeiro. 2005. 
TAKAHASHI, S. Y; et al. Método fotográfico para avaliação e controle da postura. Revista Brasileira de Reumatologia, v. 32, 1992.

TRIBASTONE, F. Tratado de exercícios corretivos: aplicados a reeducação motora postural. São Paulo: Manole, 2001.

VIEIRA, E. R.; SATO, T. O.; GIL COURY, H. J. C. Confiabilidade de uma nova técnica para mensuração do movimento de flexão anterior da coluna lombar. In: Congresso Brasileiro de Biomecânica. v. 1, p. 8994. 2001.

ZAPATER, A. R. et al. Postura sentada: a eficácia de um programa educacional para escolares. Revista ciência e Saúde Coletiva, Rio de Janeiro, v. 9, n.1, p. 191- 199. 2004 
Ivete de Aquino Freire

Universidade Federal de Rondônia- UNIR

Tatiane Gomes Teixeira

Universidade Federal de Rondônia- UNIR

Célio Reis Sales

Universidade Federal de Rondônia- UNIR

Artigo recebido: 11/04/2008

Ao parecerista: 09/06/2008

Aceito: 30/06/2008 